Petronia POPA PETRAR

Faculty of Letters, Babeș-Bolyai University Cluj-Napoca,

Romania

petronia.petrar@ubbcluj.ro

Carmen BORBELY

Faculty of Letters, Babeș-Bolyai University Cluj-Napoca,

Romania

carmen.borbely@ubbcluj.ro

\title{
REMEMBERING THINGS PRESENT: THE MATTER OF MEMORY
}

Recommended Citation: Popa Petrar, Petronia, Borbely, Carmen. "Remembering Things Present: The Matter of Memory.” Metacritic Journal for Comparative Studies and Theory 7.1 (2021): https://doi.org/10.24193/mjcst.2021.11.01

\begin{abstract}
The argument behind our introductory essay, as well as behind our special issue of the Metacritic Journal for Comparative Studies and Theory, is that the human can emerge as part of the texture of the world only by being reminded of and by objects, that is, only by engaging in a dialogue with them, by recognising both their strangeness and their familiarity, by conferring upon them the distinction of containing the traces and archives of individual and collective history. We examine the turn towards things enacted by recent critical and artistic trends as a complex amalgam of de-anthropocentrising modes recalibrating experience under the pressure of imminent extinction (of humans, animals, inanimate objects) which produces a new imperative of togetherness by excavating the memory of our shared materiality.
\end{abstract}

Keywords: things, objects, material memory, trace, nonhuman

In David Mitchell's 2001 numbergdream, a coming-of-age story that also triumphantly marks the entry of British novel writing in the new millennium, the protagonist starts what would turn out to be an unconventional (and hopeless) quest for his origins with a gesture of material violence. Eiji's rage is directed against the wooden statue of the "thunder god," whom he had promised anything in exchange for winning a football match for his team. Because his twin sister dies during the match while trying to swim into the sea towards the "whalestone" (a rock which the kids' 
imaginations had turned into a possible magical vehicle that would eventually carry them to their parents), young Eiji takes revenge on the statue by sawing its head off. This foundational scene, recounted belatedly, in fragments, and repeatedly resurfacing, haunts both the narrator's memories and the act of storytelling itself, as it condenses the complex tensions at work in the current redefinition of what counts as "human" or as "real:"

The fibres in the neck of the thunder god tear, snap and scream. I am still gripping it I never expected it to come loose so soon. It comes away, the saw goes clattering down, I reshift my weight too far, lose my balance and slide down between his back and the shrine wall. I seem to be falling for the longest time. The floor of the shrine whacks the breath out of my body. I don't break my back, but within an hour I will have turned into the incredible walking bruise. My enemy's head rolls away, wood on wood, and comes to a rest on its side, looking right this way. [...] One, two, three - I watch the severed head of the thunder god, all the way down. It vanishes in a white crown. Now I must vanish too (Mitchell 92).

Sharing a fragile, pulsating physicality - wooden fibres and human blood - that temporarily arrests the drifting configurations of geography, history, culture and psychology, subject and object come together, fall and vanish, only to resurge in shifting formations that eventually dissolve the unity of the narrative and do away with the reader's capacity to stabilise the ontology of the fictional universe (it is at times impossible to distinguish between the protagonist's fantasies and his reality). Eiji's smashing of the idol will not result in a more "authentic" self-fashioning, as the conventions of the Bildungsroman since the Enlightenment might have suggested. Initially, Eiji replaces the material encapsulation of tradition and personal trauma represented by the statue with the hyperreal, simulated landscape of high-tech Tokyo; ironically however, the end of his journey consists of a return to the agricultural island of Yakushima, home of the thunder god, whose head has in the meantime been restored, while the "tourist department" has not neglected to put "his new face on pamphlets" (415). Caught between the unreality of tradition and the derealisation prompted by consumerist, technological late modernity, the object-god persists both as a repository of stories and as an impenetrable outsider to human lives. The wooden idol's silence, simultaneously demanding and alienating, captures the strangeness of things, their instrumentalization as objects, their participation as agents in the texture of the world, and, finally, their resistance to human understanding. It is no coincidence 
that numbergdream ends with a famous blank page teasingly presented as "Chapter Nine," preceded by the announcement of a (dreamt? actual?) catastrophic earthquake that might have erased Eiji's new Tokyo life out of existence. The materiality of the empty page stands as mute witness to the imbrications of things and stories and to their dominion over what we have for so long taken as the supremacy of the human.

With Eiji's dealings with the thunder god, Mitchell's writing echoes Michel Serres musing, during the late 1980s, in Statues: "Man comes from things. He still knows it." (119) For Serres, despite the whole tradition of Western philosophy, and despite the sites for power struggles that language affords, "the constitutive condition of the subject" is not the logos, not even speech (it might be worth pointing out that in numbergdream the thunder god is not provided with a mythology, and its sound is not a language, but a physical phenomenon): it is the "humble and silent arrival" of the "tangible, visible, concrete, fearsome" object (119). Bones, statues, plates, slabs, stones: the geology of a deathly barrier whose formidable opposition summons humanity into being both as thinking subject and as meek subject to the impassability of things. Serres traces the fossils of this continuous making and breaking of the subject, forever reminded of its own objecthood by the mortuary inexorability of statues, from the ritual worshipping of the ancient god Baal, whose gigantic statue swallowed the bodies of living children (3), via a nineteenth-century story of progress imagined by Jules Verne (where people travel to the moon inside a metal shell fired by a huge cannon, accompanied by the dead body of a dog expelled from the inside, but pulled by the laws of gravity to haunt its former masters) (15), up to the hypermediatised tragedy of the rocket Challenger, which exploded upon take-off in 1987, killing the whole crew (2). Under the weight of objects, the fantasies of anthropocentrism unveil themselves as illusions of mastery, dismantled by the unremitting exchanges with the stability of matter, whether found or made by us.

Serres's seminal insights continue to prove fruitful for a variety of schools of thought, not all of them entirely compatible, but all having in common the goal of facing the new demand for "the real" under the pressure of both the new ecological awareness and the increasing "virtualisation" of the world. Let us look briefly (and somewhat arbitrarily) at a few examples. In an essay dedicated to "Thinking things," Steven Connor asks the question "How does one become a subject?" (2010, 3). The answer comes immediately and definitively: "By means of the objects one takes oneself for" (3). Following Serres, Connor explores the co-constitutionality of subject and 
object, based on the premise that it is only when we are confronted with the impenetrability of things that the subject-object continuum moulds the human in a process that is "both inaugural and ongoing" (4) and that propels it out of itself. It is safe to assert that the intense scrutiny of both things as the opaque solidity which disrupts the self-sufficiency of knowledge, and objects as the phenomenological foci of consciousness (Brown 2001; 2016) emerges in the wake of the sweeping reconceptualisation of the human during the past decades. New ethical forms of attention are paid to things, which Bill Brown (2016), in a Heideggerian vein, distinguishes from objects, defined as always, the result of human representation and usage. According to Brown, it is the "otherness" of things, "in excess of any manifest object," which "inheres as a potentiality within any object," (5) and is revealed when tools break down, or when the functionality of objects is interrupted, that recharts ontological hierarchies and interrupts the stability of the world (24). It is worth pointing out, for our present purposes, Brown's insistence on the hospitality of art and literature to "thingness": it is here that "the character of things has been preserved, awaiting its excavation" (26). Although not sharing the same fundamental assumptions, the increasingly wider field of object oriented ontology takes as a "central principle" a similar "withdrawal or withholding of things from direct access" (Harman 13), coupled with the premise that objects (in Harman's and his colleagues' view, the terms are synonymous), which make up the substratum of the world and can be either material or immaterial, "real" or "fictional," are independent with respect to each other, rather than coexisting in mutual relations (Harman 18). While this latter point is more than debatable from the perspective of an ecological kind of thought that we find far preferable, such tenets have the merit of proposing a "a democracy of things" described as a "flat ontology" which "invites us to think in terms of collectives and entanglements between a variety of different types of actors, at a variety of different temporal and spatial scales, rather than focusing exclusively on the gap between humans and objects" (Bryant 32).

It is no coincidence that the same period has witnessed the reconfiguration of memory studies in the direction of recasting memory itself less as an "object" of research, and more as "part of larger networks and 'media ecologies' subject to boundless variations and remediations" (Knittel and Driscoll 2017, 381). This reconfiguration has been forced by the awareness of the reification and commodification of everything material under the conditions of late-stage capitalism, 
which feeds the shapeless non-place of waste (Scanlan 2005, 20) with an inflation of discarded objects (or their remainders) that muddles the retrospective tug of memory. The unabated accumulation of residual matter perturbs the recollective force of things, lost in the amorphousness of the junkyard.

Faced with the abundance of objects, natural and manmade, we have no choice but to follow Bruno Latour and recognise our imbrication in networks of what F. Allan Hanson called "composite agency" (56), conditioning what and how we remember. As the editors of The Future of Memory also suggest, memory may well be "one of the things that makes us human," but thingness as a trigger of remembrance demands a "return to the question that has consistently animated its trajectory: man's inhumanity" (Crownshaw, Kilby, and Rowland, x). This taps into a Latourian compositionist picture of blurred boundaries between the mediums and matters of a memory that cathects, rather than divides subjects and objects. At the same time, it becomes increasingly clear that Latour's notion that agency proliferates indiscriminately amidst animate and inanimate components of inextricable assemblages, releasing objects from their functional subservience to humans, either as heralds of the future $(2010,486)$ or as reminders of the past. In fact, starting from Jan Assmann's discussion of the material embeddedness of cultural memory, we can, indeed, look at things as preservers, conduits, or activators of human remembrance, but it also becomes possible to envision this recollective agency beyond the asymmetrical divide of "a remembering mind and a reminding object" $(2015,332)$. While in Assmann's view "object-memory," or the "memory of things" (both private and public) that humans coexist with in their environs, is instrumental to reconstructions of multi-layered pasts into a ceaselessly re-sedimented present (2011, 6-7), there is still a sense in which the mnemonic agency of things does not exceed what Krzysztof Pomian calls the semiophoric - i.e., meaning bearing (5) - function of museal, archaeological or archival items: these are, in a way, cleansed of their sticky materiality and abstracted into signifiers of their "invisible" other space-times (24).

Leaving behind the assumption that the objects' "corporeity or materiality" (Pomian 24) is a medium for the production and consumption of human-centred meaning, archaeologist Ian Hodder sees the relations between beings and things as intricate, inextricable and inescapable. Because of the vastly different yet embroiled timeframes of humans and nonhumans, Hodder believes that our enmeshment with the thingness of the world makes us oblivious to objects accumulating or dissipating a 
memory of their own. This illusory affixing of human memory in an utterly unstable, endlessly changing materiality of the world is suggestively captured in Hodder's idea of entanglement-qua-entrapment, predicated upon a "retreat from an entirely relational treatment of matter, to rediscover the object nature of things" (33). Simply put, Hodder says, what this means for our contemporary ecological predicament is that only within a short-term span can humans hope to reboot the memory of an environment that "is not just a backdrop within which we fix problems" but a site of memory "actively involved in our being as a species" (34). In the long term, therefore, it is quite likely that our irreversible, "colossal entanglements" with the things that archive the memory of our humanity ("we are only human through things") may, in turn, trap the spectral traces of our bygone existence within the layers of pollutants, nuclear waste, and plastic (34).

As seen above, objects as "storehouses of memory" (Yates 294) simultaneously constitute and transcend the capacity of the human to capture the past, crystallise the present or project a future. Whether we revel in things as "vibrant matter" (Bennett 3) or as examples of the radically unknowable (Hodder 33), things can cease being simple mnemonic devices and may also reveal themselves as causes of forgetfulness, their presence urgently placing us in coextensive webs of meaning and action. In a fluid world where technological prostheses, the viral propagation of bodies, codes and signifiers and the trappings of the "post-truth" era trigger historical amnesia, we turn to objects both as repositories of personal and collective recollection, and reminders of our immersion in the substantial and the concrete, a co-participation biologically inscribed in the very makings of our bodies. Not least, it appears that the nonanthropocentric focus on the materiality of memory can compel a fundamental reframing of "things" themselves as alert to memory's dynamic futurity (Zirra 469).

However, just as we acknowledge our embeddedness in a material world that supports the mnemonic scaffolding of our minds, memory tends to be less and less confined, within cyberreality regimes, to the static sites of storage discussed by Anne Whitehead in her overview of mnestic landscapes (11). Memory is dynamic, not only by virtue of its enfolding past and present temporalities within acts of reminiscence and recollection. It moves "unbounded" between the computer hard drive and the digital cloud, analogue annals and electronic databases that spur our contemplation of the haunting spectrality of the archive and the "disappearance of material history into digital code" (Kroker 81). Photographs of quotidian experience uploaded on social 
networking sites convey the outmodedness of albums, recipe books, souvenirs, and keepsakes. Digitalised images of museums accessible online eliminate the desire to visit museal places and see objects of memory on display, as the loci memoriae "shrink" in museums and as the showcased artefacts perform "vanishing acts," vacating space for the sake of interactive experiences with virtual, dematerialised copies (Conn 22-24). Simulated sociality in pandemic times is reminiscent of face-toface interactions, anticipating, supplanting or postponing the return to materially mediated human/nonhuman relations. The surfeit of digital memory expands indefinitely. With no time or space limits to constrain its flow, it encompasses "broadcaster websites of archival material, blogs, digital storytelling, passwords, computer games based on past wars, fan sites and digital scrapbooks" (Garde-Hansen, Hoskins and Reading 4). What digital mnemonic processes such as "keeping track, recording, retrieving, stockpiling, archiving, backing-up and saving” generate is, paradoxically, "information loss," materialising "one of our greatest fears" of recent times (5). Indeed, it appears that both the excessive materiality of the junkyard (the ocean that accumulates plastic and different other pollutants, the landfill that amasses unmanageable quantities of waste, or the earth's atmosphere that absorbs carbon emissions) and the digital drift of memory promote an art of oblivion, as

it is possible to forget on account not of defect but of excess, just as, though it is not possible to destroy the meaning of an assertion pronounced aloud, it is possible to pronounce another assertion in the same moment, so that the two assertions are superimposed. There are no voluntary devices for forgetting, but there are devices for remembering badly (Eco and Migiel 260).

Are spontaneous forgetting and poor remembrance the jokes or jeopardies of today's digital memory? According to Bond, Craps, and Vermeulen, memory in the digital age "does not stay put but circulates, migrates, travels; it is more and more perceived as a process, as work that is continually in progress, rather than as a reified object” (1). It is increasingly conceptualised as leakage, outflow, or as drift, which is "transcultural, transgenerational, transmedial, and transdisciplinary" (2). This heightens the need to ponder the changes invited by memorialising practices that tend to be globally rather than locally oriented, by forms of memory that enable the communication of trauma from one generation to the next, by plurimodal remediations of commemoration, or 
by the multiplicity of discursive constructions of memory under conflicting regimes of digitality and materiality (Bond, Craps, and Vermeulen 3-23).

Taking into account all this, the papers gathered under the heading "The Objects of Memory, the Memory of Objects" in this issue of the Metacritic Journal for Comparative Studies and Theory engage with the possibility of considering the role of objects beyond that of passive triggers of spontaneous or cultivated remembrance, because things reveal their agentive capacity to store, transmit, block or shape memory and to function as nodes at the multiple intersections between the human and the nonhuman. The variety of the approaches hosted by this issue of the journal is evidence not of a scattered state of the field, but, on the contrary, of an exciting common denominator traversing diverse forms of thought and feeling, both theoretical and artistic. Christian Moraru's essay sets the foundations of a "flat aesthetics," consonant with a "democratic" arraignment of the world, which abandons archaeological or demystifying attempts at interpretation in favour of a "prismatic" irradiation of adjacent objects. Moraru's view on literature as an object among others is complemented by Maryam Muliaee's essay, which considers "media-as-things," rendering visible the imbrications of objectual agencies and the audience's sensorial and affective responses. Daniel Clinci's thought-provoking essay outlines the insidious ways in which plastic, the ultimate material commodity of the past century or so what we might call, following Timothy Morton, a hyperobject, given its ingrained obsolescence and indefinite persistence $(2013,1)$ - amasses its widely disseminated traces into layers of geological memory that may eventually survive as sole witnesses to tell a cautionary tale of "human exceptionalism." In ways that are reminiscent of Hirsch and Spitzer's thoughts on the role played by artefacts as archival supplements of trauma testimonies (2006), Eleonora Sava's examination of family cookbooks reveals their quality as sensory objects that created and protected family memory against the volatility of life in communism and postcommunism. Alexandru Matei's paper explores one of the philosophical roots of the material turn in Michel Serres's work by reviving the notion of "integumentum," while other pieces function as case studies of diverse forms of "thingness:" war memorial sites and their role in constructing historical memory (Andrea Roxana Bellot), BrexLit and embodied memory (Dana Percec), eighteenth-century commodity fetishism (Dragoș Ivana), memorialising mechanisms (Ana Țăranu), posthuman embodiment in contemporary fiction (Alina Preda), bodily markers of memory (Ágnes Zsófia Kovács), thingly 
cognition and empathy (Andreea Beleuță), personal and communal forms of loss spatialised and timed by things (Andrei Bogdan Popa), corporeal memory in the novels of Yoko Ogawa, Han Kang, Olga Tokarczuk (Lavinia Tache), and the derealisation of the subject by its own commodification of objects (Florina Ilis).

\section{References:}

Assmann, Jan. Cultural Memory and Early Civilisation. Writing, Remembrance, and Political Imagination. Cambridge University Press, 2011.

---. "Memory and Culture." Memory. A History. Ed. Dmitri Nikulin. Oxford University Press, 2015: 325-350.

Bennett, Jane. Vibrant Matter: A Political Ecology of Things. Duke University Press, 2009.

Bond, Lucy, Stef Craps, and Pieter Vermeulen. Memory Unbound. Tracing the Dynamics of Memory Studies. Berghahn Books, 2016.

Brown, Bill. “Thing Theory," Critical Inquiry 28.1 (2001): 1-22.

---. Other Things, University of Chicago Press, 2016.

Bryant, Levi R. The Democracy of Things. Open Humanities Press, 2011.

Conn, Steven, Do Museums Still Need Objects? University of Pennsylvania Press, 2010.

Connor, Steven. "Thinking things," Textual Practice 24.1 (2010): 1-20.

Crownshaw, Richard, Jane Kilby, and Antony Rowland. The Future of Memory. Berghahn Books, 2010.

Eco, Umberto, and Marilyn Migiel. “An Ars Oblivionalis? Forget It!” PMLA 103.3 (1988): 254-261.

Garde-Hansen, Joanne, Andrew Hoskins, and Anna Reading. Save As... Digital Memories. Palgrave Macmillan, 2009.

Hanson, F. Allan. "Which Came First, the Doer or the Deed?" The Moral Status of Technical Artefacts. Ed. Peter Kroes, Peter-Paul Verbeek Springer, 2014: 55-73.

Harman, Graham. Object Oriented Ontology. A New Theory of Everything. Penguin, 2017.

Hirsch, Marianne, and Leo Spitzer. "Testimonial Objects: Memory, Gender, and Transmission." Poetics Today 27.2 (2006): 353-83.

Hodder, Ian. "The Entanglements of Humans and Things: A Long-Term View." New Literary History 45.2 (2014): 19-36. 
Knittel, Susanne C., and Kári Driscoll. "Introduction: Memory after Humanism," Parallax 23. 4 (2017): 379-83.

Kroker, Arthur. Exits to the Posthuman Future. Polity Press, 2014.

Latour, Bruno. “An Attempt at a 'Compositionist Manifesto'.” New Literary History, 41. 3 (2010): 471-90.

Mitchell, David. numbergdream. Sceptre, 2002.

Morton, Timothy. Hyperobjects. Philosophy and Ecology after the End of the World. University of Minnesota Press, 2013.

Pomian, Krzysztof. Collectors and Curiosities. Paris and Venice, 1500-180o. Polity Press, 1990. Trans. Elizabeth Wiles-Portier.

Serres, Michel. Statues. The Second Book of Foundations. Bloomsbury, 2015. Trans. by Randolph Burks.

Scanlan, John. On Garbage. Reaktion Books, 2005.

Whitehead, Anne. Memory. Routledge, 2009.

Yates, Frances A. The Art of Memory. Ark Paperbacks, 1984.

Zirra, Maria. "Shelf Lives: Nonhuman Agency and Seamus Heaney's Vibrant Memory Objects.” Parallax 23. 4 (2017): 458-73. 